\title{
Gut Microbiota: The Missing Link in Obesity Induced Nonalcoholic Liver Disease
}

\author{
Roma Rattan ${ }^{1}$, Purnendu Panda ${ }^{2}$, Srikrushna Mahapatra ${ }^{3}$ \\ ${ }^{I}$ Assistant Professor, Department of Biochemistry, S.C.B. Medical College, Cuttack \\ ${ }^{2}$ Postgraduate Student, Department of Biochemistry, S.C.B. Medical College, Cuttack \\ ${ }^{3}$ Professor and H.O.D, Department of Biochemistry, S.C.B. Medical College, Cuttack
}

\begin{abstract}
Background and objective: Recent research has elucidated a close association between intestinal microbiota, obesity, insulin resistance and nonalcoholic hepatic injury. Various studies have also indicated an increase in hepatic marker enzymes in obesity. Hence, this study aims to evaluate the association of gut microbiota with obesity, insulin resistance and hepatic marker enzymes.

Material and Method: This case-control study was conducted during March 2015 to October 2016 At S.C.B Medical College, Cuttack, Odisha. The study included 186 subjects (86 irritable bowel syndrome patients as per the Rome III criteria and hundred matched controls). Plasma fasting glucose, serum lipid profile, hepatic marker enzymes were analysed by commercial kits adapted to automated clinical chemistry analyser and serum fasting insulin was estimated by kits adapted to Lisa Scan.

Observation: Compared to controls the Irritable bowel syndrome patients had significantly higher Body mass index (20.9 $\pm 5.6 \mathrm{vs} 30.1 \pm 0.22)$, Waist-hip ratio (0.9 $\pm 0.11 \mathrm{vs} 1.02 \pm 0.06)$, lipid profile, hepatic marker enzymes and insulin resistance.

Conclusion: IBS patients were obese, and exhibited dyslipidemia, insulin resistance, elevated hepatic enzymes suggesting development of NAFLD.
\end{abstract}

Keywords: Irritable bowel syndrome, liver enzymes, obesity, nonalcoholic liver disease

\section{Introduction}

Recent research has revealed a close association between intestinal microbiota and host metabolic pathways (1-3). Various studies have revealed the association of intestinal microbiota with insulin resistance and obesity induced hepatic disease (4-5). The increase in intestinal microbiota cause irritable bowel syndrome (IBS) (6). IBS is illustrated by the following features- abdominal pain, discomfort, altered bowel habits without any detectable organic disease (7). IBS is commonly observed in the general population with a global prevalence of 7-30 \% and its prevalence \& incidence in India is 4 to $4.2 \%(8,9,10,11)$. The pathophysiology of IBS is not clear and various hypotheses have been suggested, such as alterations in the intestinal microbiota, dysfunction of the gut-brain axis \& autonomic nervous system, genetic predisposition, visceral antipathy, altered gastrointestinal hormones and obesity $(12,13)$. Various studies have indicated an association of increased intestinal bacteria with IBS and increased permeability of the intestine $(14,15)$. Intestinal permeability may be increased in the high fat diet of obesity (16). These metabolic alterations of increased microbiota and obesity lead to nonalcoholic fatty liver disease [NAFLD] $(17,18)$. Schnabl and Brenner suggested that the intestinal microbiota cause injury to the intestinal barrier and increase the permeability of bacterial endotoxins induce and help in progression of NAFLD (19). Hence, this study aims to evaluate the association of gut microbiota with obesity, insulin resistance and hepatic marker enzymes.

\section{Material and Method}

This case-control study was conducted during March 2015 to October 2016 At S.C.B Medical College, Cuttack, Odisha. The study included 186 subjects ( 86 irritable bowel syndrome patients as per the Rome III criteria and hundred matched controls). The IBS patients were further classified as per the Rome III criteria into IBS-C (constipation -predominent), IBS-D (diarrhea- predominent), IBS-M (mixed) and IBS-U (unsubtyped). As per the Rome III criteria, IBS is defined as recurrent abdominal discomfort or pain, at least for 3 days per month for 3 months with onset six months prior to diagnosis and associated with the following characteristics: (a) improvement with defecation, (b) onset associated with change in stool frequency, (c) onset associated with change in stool consistency $(9,20)$.

The anthropometric measurements were done while the study subjects were in light clothing and without shoes. Body mass index was calculated as weight in Kgs divided by height in meter ${ }^{2}$. The waist circumference was assessed in the midway of the 12th rib and iliac crest. Blood pressure was measured after resting for 15 minutes. Venous blood samples were collected after overnight fast. Fasting blood sugar, lipid 
profile, liver function test parameters were done by commercial kits adapted to Toshiba 120 FR autoanalyser. Serum fasting insulin was estimated by kits adapted to Lisa Scan. Insulin resistance was calculated by using the HOMA IR formula. HOMA index = fasting insulin $(\mu \mathrm{U} / \mathrm{ml}) \mathrm{X}$ fasting blood sugar $(\mathrm{mg} / \mathrm{dl}) / 405$. The HOMA index includes measurement of fasting plasma insulin and glucose and is calculated from these two parameters. The reference range of HOMA index is as follows:

$>2.0$ indication for insulin resistance

$>2.5$ insulin resistance probable

$>5.0$ average value in patients with diabetes mellitus type 2

\section{Statistical Analysis}

All the data are represented as mean \pm standard deviation. An unpaired student's t test was done to compare the data. Pearson's correlation analysis was done to find the association. SPSS version 19 was used for all statistical analysis.

\section{Results}

The baseline demographic data of the study population is described in table 1. All the IBS patients were obese and had significantly higher BMI and waist hip ratio (WHR) as compared to the controls. Table 2 depicts the comparison of various biochemical parameters between the IBS patients and the control population. We observed a significant higher BMI and WHR in the IBS patients. We perceived statistically significant high serum total cholesterol, triglyceride, LDL cholesterol level in the IBS patients as compared to the heathy controls. The hepatic enzymes were significantly high in the IBS patients though Serum total bilirubin was within the normal range. The IBS patients were observed to have significant insulin resistance as shown by a higher HOMA IR level. Figure 1 shows the increase in hepatic enzymes

Table 1 Demographic data of the study population

\begin{tabular}{|l|l|}
\hline Parameters & \\
\hline Age in years & $46 \pm 5.4$ \\
\hline Gender & male \\
\hline BMI: IBS patients vs controls & $30.1 \pm 0.22$ vs $20.9 \pm 5.6^{*}$ \\
\hline Waist hip ratio: IBS patients vs controls & $1.02 \pm 0.06$ vs $0.9 \pm 0.11^{*}$ \\
\hline Systolic blood pressure $\mathrm{mm}$ of $\mathrm{Hg}$ & $118 \pm 2.66$ \\
\hline Diastolic blood pressure $\mathrm{mm}$ of $\mathrm{Hg}$ & $80 \pm 6.66$ \\
\hline
\end{tabular}

Table 2 Comparison of biochemical parameters between the IBS patients and Controls

\begin{tabular}{|l|l|l|}
\hline Parameters & IBS patients & Controls \\
\hline Fasting blood sugar (mg\%) & $102 \pm 1.22$ & $98 \pm 3.1$ \\
\hline Total cholesterol (mg\%) & $212 \pm 0.12$ & $156 \pm 0.56^{*}$ \\
\hline Triglycerides $(\mathrm{mg} \%)$ & $258 \pm 1.86$ & $104 \pm 1.28^{*}$ \\
\hline HDL Cholesterol (mg\%) & $56.2 \pm 0.89$ & $49.4 \pm 0.66$ \\
\hline LDL Cholesterol (mg\%) & $167 \pm 1.46$ & $111 \pm 2.4^{*}$ \\
\hline VLDL Cholesterol (mg\%) & $45.6 \pm 0.24$ & $20 \pm 0.21$ \\
\hline Total bilirubin (mg\%) & $0.5 \pm 0.02$ & $0.5 \pm 0.01$ \\
\hline Alanine aminotransferase (IU/L) & $42.1 \pm 12.4$ & $24 \pm 10.2^{*}$ \\
\hline Aspartate aminotransferase (IU/l) & $39.9 \pm 7.1$ & $20.1 \pm 5.4^{*}$ \\
\hline Alkaline phosphatase (IU/l) & $126.2 \pm 14.2$ & $92.4 \pm 1.66^{*}$ \\
\hline Gamma Glutamyl transferase (IU/L) & $47.9 \pm 1.4$ & $30.6 \pm 8.5^{*}$ \\
\hline HOMA IR & $2.2 \pm 0.2$ & $1.0 \pm 0.6^{*}$ \\
\hline
\end{tabular}

Figure 1

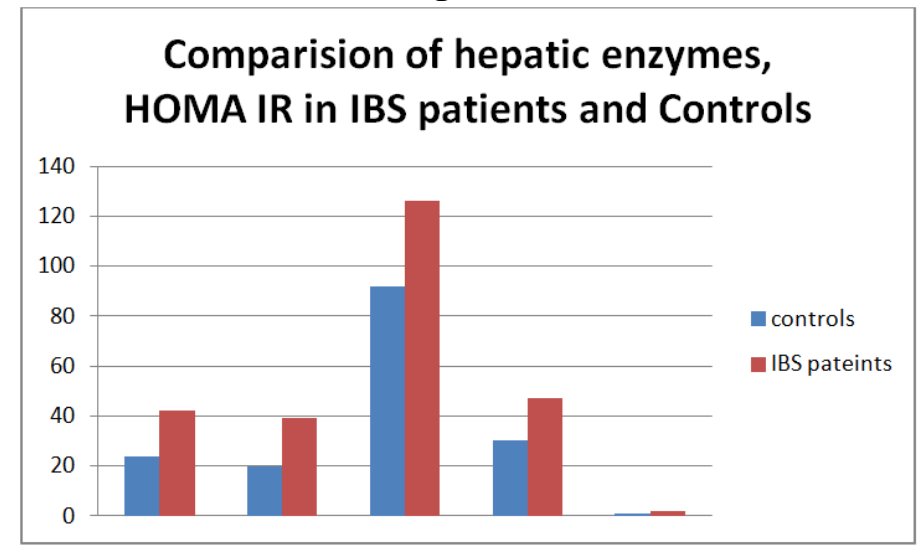




\section{Discussion}

We observed elevated hepatic enzymes in the IBS patients in this case control study. Our observation is similar to various previous studies $(21,22$, and 23). Various studies have observed in the IBS, the intestinal microbiota is altered and there exists an overgrowth of the Gut microbiota (23). This causes increase release of bacterial endotoxins and alterations of the tight junctions leading to alterations in the intestinal permeability. The increased permeability leads to elevated bacterial endotoxins in the serum, which causes the release of proinflammatory molecules such as Tumor necrosis factor alpha and nitosative stress (19 - 18). These proinflammatory molecules and nitrosative stress induce hepatic injury which is observed by elevated hepatic enzymes.

Though few studies have examined the association of IBS and obesity, the pathophysiology is not completely elucidated. However, in vitro studies have suggested various mechanisms, which illustrate the lipid lowering role of intestinal microbiota, Bifidobacterium, in humans (29, 30). The end-products of bacterial fermentation, cholesterol assimilation, bile acid secretion help in lipid metabolism but in obesity alteration of intestinal microbiota affects lipid excretion (30). The endotoxins derived from intestinal bacteria link inflammation, insulin resistance to the high fat diet in obesity $(29,30)$. The bacterial endotoxins cause release of monocyte chemoattractant protein-1 which activates monocytes and releases various cytokines leading to inflammation, oxidative stress and insulin resistance (30). The dyslipidemia cause lipid deposition and NAFLD as seen by elevated hepatic enzymes.

In conclusion, we suggest estimation of bacterial endotoxins, in obese IBS patients and taking preparatory measures in reducing the alterations in intestinal bacteria as a preventive measure for NAFLD.

\section{Conflict of interest None}

\section{Acknowledgements}

Authors acknowledge the cooperation received from patients, volunteers and the help received from the scholars whose articles are cited and included in the references of this manuscript.

\section{Reference}

[1]. Caricilli AM, Saad MJ. The role of gut microbiota on insulin resistance. Nutrients 2013;5:829-51.

[2]. D’Aversa F, Tortora A, Ianiro G, Ponziani FR, Annicchiarico BE, Gasbarrini A. Gut microbiota and metabolic syndrome. Intern Emerg Med 2013;8 Suppl 1:S11-5.

[3]. Le Roy T, Llopis M, Lepage P, Bruneau A, Rabot S, Bevilacqua C, et al. Intestinal microbiota determines development of nonalcoholic fatty liver disease in mice. Gut 2013;62:1787-94.

[4]. Gerritsen J, Smidt H, Rijkers GT, de Vos WM. Intestinal microbiota in human health and disease: the impact of probiotics. Genes Nutr 2011;6:209-40.

[5]. Cholongitas E, Pipili C, Dasenaki M. Gastro-oesophageal reflux disease and irritable bowel syndrome significantly associated with metabolic syndrome. Scand J Gastroenterol 2008;43:1405-6.

[6]. Collins SM. Translating symptoms into mechanisms: functional GI disorders. Adv Physiol Educ 2007;31:329-31

[7]. Agrawal A, Whorwell PJ. Irritable bowel syndrome: diagnosis and management. BMJ 2006;332:280-3.

[8]. Drossman DA, Li Z, Andruzzi E, Temple RD, Talley NJ, Thompson WG, et al. U.S. householder survey of functional gastrointestinal disorders. Prevalence, sociodemography, and health impact. Dig Dis Sci 1993;38:1569-80

[9]. Saito YA, Locke GR, Talley NJ, Zinsmeister AR, Fett SL, Melton LJ 3rd. A comparison of the Rome and Manning criteria for case identification in epidemiological investigations of irritable bowel syndrome. Am J Gastroenterol 2000;95:2816-24

[10]. Ghoshal UC, Abraham P, Bhatt C, Choudhuri G, Bhatia SJ, Shenoy KT et al. 2008. Epidemiological and clinical profile of irritable bowel syndrome in India: report of the Indian Society of Gastroenterology Task Force. Indian J Gastroenterol 27(1): 22-8. pmid: 18541934

[11]. Makharia GK, Verma AK, Amarchand R, Goswami A, Singh P, Agnihotri A et al. 2011. Prevalence of irritable bowel syndrome: a community based study from northern India. J Neurogastroenterol Motil. 17(1): 82-7. doi: 10.5056/jnm.2011.17.1.82. pmid:21369496

[12]. Parkes GC, Brostoff J, Whelan K, Sanderson JD. Gastrointestinal microbiota in irritable bowel syndrome: their role in its pathogene- sis and treatment. Am J Gastroenterol 2008;103:1557-67.

[13]. Ohman L, Simrén M. New insights into the pathogenesis and pathophysiology of irritable bowel syndrome. Dig Liver Dis 2007; 39:201-15.

[14]. Singh VV, Toskes PP. Small bowel bacterial overgrowth: presenta- tion, diagnosis, and treatment. Curr Treat Options Gastroenterol 2004; 7:19-28.

[15]. Szabo G, Bala S, Petrasek J, Gattu A. Gut-liver axis and sensing mi- crobes. Dig Dis 2010;28:737-44.

[16]. Magnan C, Collins S, Berthault M, Kassis N, Vincent M, Gilbert M, Penicaud L, Ktorza A, Assimacopoulos-Jeannet F: Lipid infusion lowers sympathetic nervous activity and leads to increased beta-cell responsiveness to glu- cose. J Clin Invest 103:413419, 1999

[17]. Miele L, Valenza V, La Torre G, Montalto M, Cammarota G, Ricci R, et al. Increased intestinal permeability and tight junction altera- tions in nonalcoholic fatty liver disease. Hepatology 2009;49:1877-87.

[18]. Miele L, Beale G, Patman G, Nobili V, Leathart J, Grieco A, et al. The Kruppel-like factor 6 genotype is associated with fibrosis in non-alcoholic fatty liver disease. Gastroenterology 2008; 135: 282-91.

[19]. Schnabl B, Brenner DA. Interactions between the intestinal microbiome and liver diseases. Gastroenterology 2014; 146: 1513-24

[20]. Han SH, Lee OY, Bae SC, Lee SH, Chang YK, Yang SY, et al. Preva- lence of irritable bowel syndrome in Korea: populationbased sur- vey using the Rome II criteria. J Gastroenterol Hepatol 2006;21: 1687-92.

[21]. International Diabetes Federation 2005. IDF Consensus Worldwide Definition of the Metabolic Syndrome. Accessed on: Mar 23, 2009.Available from:http://www.idf.org.br. 
[22]. Pimentel M, Chow EJ, Lin HC. Eradication of small intestinal bacterial overgrowth reduces symptoms of irritable bowel syndrome. Am J Gastroenterol 2000;95:3503-6.

[23]. Szabo G, Bala S, Petrasek J, Gattu A. Gut-liver axis and sensing microbes. Dig Dis 2010;28:737-744.

[24]. Miele L, Valenza V, La Torre G, Montalto M, Cammarota G, Ricci R, et al. Increased intestinal permeability and tight junction alterations in nonalcoholic fatty liver disease. Hepatology 2009;49: 1877-87.

[25]. Miele L, Beale G, Patman G, Nobili V, Leathart J, Grieco A, et al. The Kruppel-like factor 6 genotype is associated with fibrosis in non-alcoholic fatty liver disease. Gastroenterology 2008;135:282-91.

[26]. Harte AL, da Silva NF, Creely SJ, McGee KC, Billyard T, Youssef- Elabd EM, et al. Elevated endotoxin levels in non-alcoholic fatty liver disease. J Inflamm (Lond) 2010;7:15.

[27]. Creely SJ, McTernan PG, Kusminski CM, Fisher fM, Da Silva NF, Khanolkar M, et al. Lipopolysaccharide activates an innate immune system response in human adipose tissue in obesity and type 2 diabetes. Am J Physiol Endocrinol Metab 2007;292:E740-7.

[28]. Reid AE. Nonalcoholic steatohepatitis. Gastroenterology 2001; 121:710-23.

[29]. Guo Y, Niu K, Momma H, Kobayashi Y, Chujo M, Otomo A, et al. Ir- ritable bowel syndrome is positively related to metabolic syn- drome: a population-based cross-sectional study. PLoS One 2014; 9:e112289.

[30]. Cani PD, Amar J, Iglesias MA, Poggi M, Knauf C, Bastelica D, et al. Metabolic endotoxemia initiates obesity and insulin resistance. Diabetes 2007;56:1761-72. 